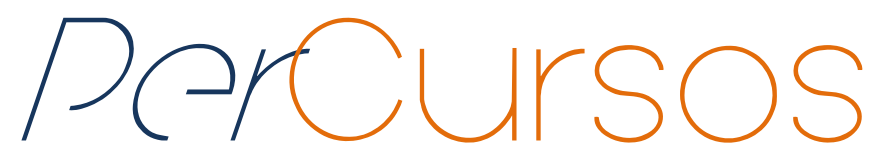

\title{
O PIBID e a formação de professores de Geografia no Sertão do Sisal: práticas, narrativas e experiências de iniciação à docência ${ }^{1}$
}

\begin{abstract}
Resumo
Neste texto, a partir de narrativas de professores de Geografia em formação inicial, intencionamos apresentar as ações que compõem a proposta do subprojeto do PIBID "Formação docente e Geografia escolar: das práticas e saberes espaciais à construção do conhecimento geográfico", em desenvolvimento na Universidade do Estado da Bahia UNEB/Campus XI, abrangendo 6 (seis) escolas - 3 (três) rurais e 3 (três) urbanas - de ensino fundamental e médio, de 3 (três) municípios do Território de Identidade do Sisal: Conceição do Coité, Serrinha e Teofilândia, e envolvendo 57 (cinquenta e sete) bolsistas, divididos em três grupos, a saber: 45 (quarenta e cinco) bolsistas de iniciação à docência, 9 (nove) bolsistas de supervisão e 3 (três) bolsistas responsáveis pela coordenação. Trata-se de uma proposta de formação que tem como principal objetivo articular a Universidade à escola básica, por meio do desenvolvimento de ações situadas no campo de formação do professor de Geografia, contempladas nas dimensões de ensino, pesquisa e extensão. O referido subprojeto, ancorado em diversas linguagens, como artefatos didático-pedagógicos e no método (auto)biográfico, potencializa outros modos de conceber a formação docente, o ensino e a aprendizagem dos conteúdos curriculares de Geografia na educação básica. As narrativas dos bolsistas de Iniciação à Docência e de Supervisão sinalizam as contribuições do PIBID à formação inicial e continuada de professores e destacam, ainda, a relevância das vivências e experiências formativas realizadas no cotidiano das escolas, no processo de aprendizagem docente.
\end{abstract}

Palavras-chave: PIBID; Formação de Professores de Geografia; Narrativas; Práticas Pedagógicas.

\section{Para citar este artigo:}

PORTUGAL, Jussara Fraga; OLIVEIRA, Simone Santos de. O PIBID e a formação de professores de Geografia no Sertão do Sisal: práticas, narrativas e experiências de iniciação à docência. Revista PerCursos, Florianópolis, v. 17, n.35, p. 04 - 27, set./dez. 2016.

\section{DOI: $10.5965 / 1984724617352016004$}

http://dx.doi.org/10.5965/1984724617352016004

\footnotetext{
${ }^{1}$ Projeto Programa Institucional de Bolsa de Iniciação à Docência - PIBID, com apoio da Coordenação de Aperfeiçoamento de Pessoal de Nível Superior - CAPES/MEC.
} 


\title{
The PIBID and Geography teacher training in the Sisal Sertão: practices , narratives and initiation experiences to teaching
}

\begin{abstract}
In this text, from narratives of Geography teachers in initial training, we intend to present the actions that make up the proposed subproject PIBID "Teacher training and school Geography: practices and spatial knowledge to the construction of geographical knowledge" in development at the University of State of Bahia - UNEB / Campus XI, which behaves in six (6) schools - three (3) rural and three (3) urban elementary and high school, three (3) municipalities of the Sisal Identity Territory: Conceição do Coité, Serrinha and Teofilândia and involves 57 (fifty seven) fellows, divided into three groups, namely: 45 (forty five) initiation scholarship to teaching, nine (9) supervision of fellows and three (3) fellows responsible for coordinating. This is a training proposal that aims to articulate the university to primary school, through the development of actions on the field of teacher of Geography, included in the dimensions of teaching, research and extension. Said sub-project, anchored in different languages such as didactic and pedagogical artifacts and method (auto) biographical, potentiates other ways of conceiving teacher training, teaching and learning curricula of geography in basic education. The narratives of the fellows from initiation to teaching and supervisory signal the PIBID contributions in initial and continuing teacher training and also highlight the relevance of experiences and formative experiences in primary education schools, the teaching of the learning process.
\end{abstract}

Keywords: PIBID; Geography Teacher Training; Narratives; Pedagogical Practices. 


\section{O contexto do texto: uma introdução}

A Universidade do Estado da Bahia - UNEB é uma instituição de ensino superior que desempenha historicamente um significativo papel na formação de professores. Criada em $1^{\circ}$ de junho de 1983 e reconhecida pelo Ministério da Educação em 31 de junho de 1995 como uma organização multicampi, a UNEB é considerada a maior instituição pública de ensino superior do estado da Bahia, estando presente geograficamente em 18 (dezoito) dos 27 (vinte e sete) Territórios de Identidade ${ }^{2}$ do território baiano. Conta, atualmente, com 24 (vinte e quatro) Campi e 29 (vinte e nove) Departamentos localizados em sedes de 24 (vinte e quatro) municípios baianos, incluindo a cidade de Salvador, capital do estado, que abriga a sede da Administração Central da Instituição. Além dos Campi, a UNEB marca presença na quase totalidade dos 417 (quatrocentos e dezessete) municípios do estado, por intermédio de programas e ações extensionistas, em convênio com organizações públicas e privadas. A Universidade disponibiliza mais de 150 (cento e cinquenta) opções de cursos e habilitações, nas modalidades presencial e de educação a distância (EaD), nos níveis de graduação e pós-graduação, oferecidos em 29 (vinte e nove) Departamentos.

A inserção da UNEB no Programa Institucional de Bolsa de Iniciação à Docência (PIBID/CAPES) $)^{3}$ deu-se em 2009, através da aprovação do projeto A docência partilhada:

\footnotetext{
${ }^{2}$ O Território de Identidade é uma unidade de planejamento adotada no estado da Bahia, Brasil, a partir do ano de 2008, no primeiro Governo Jaques Wagner. A partir desse novo modelo, o estado da Bahia passou a ser reorganizado por 26 (vinte e seis) Territórios de Identidade, e a inclusão de mais um, no ano de 2012. Esta delimitação é baseada nos propósitos do Programa Nacional de Desenvolvimento Sustentável dos Territórios Rurais (PNDSTR), apresentada pelo Ministério de Desenvolvimento Agrário (MDA)/Secretaria de Desenvolvimento Territorial (SDT). Neste contexto, segundo a Secretaria de Planejamento do Estado da Bahia - SEPLAN (2008), o Território de Identidade é concebido como "um espaço físico, geograficamente definido, geralmente contínuo, caracterizado por critérios multidimensionais, tais como o ambiente, a economia, a sociedade, a cultura, a política e as instituições, e uma população com grupos sociais relativamente distintos, que se relacionam interna e externamente por meio de processos específicos, onde se pode distinguir um ou mais elementos que indicam identidade, coesão social, cultural e territorial".

${ }^{3}$ Programa que concede bolsas a estudantes de licenciatura, financiado pela Coordenação de Aperfeiçoamento de Pessoal de Nível Superior - CAPES, tem como, principais objetivos: 1) incentivar a formação de docentes em nível superior para a educação básica; 2) contribuir para a valorização do magistério; 3) elevar a qualidade da formação inicial de professores nos cursos de licenciatura, promovendo a integração entre educação superior e educação básica; 4) inserir os licenciandos no cotidiano de escolas da rede pública de educação, proporcionando-lhes oportunidades de criação e
} 
Universidade e escola como espaços que favorecem a construção dos elementos essenciais à docência, ${ }^{4}$ a partir do Edital $n^{\circ}$ 02/2009 - CAPES/DEB. O referido projeto institucional definiu como objetivo principal promover a inserção dos estudantes das licenciaturas no cotidiano das escolas, a fim de compreender a docência em suas diferentes e complexas dimensões, contemplando 11 (onze) subprojetos em 9 (nove) campi ${ }^{5}$ e 210 (duzentos e dez) bolsistas de iniciação à docência, 23 (vinte e três) coordenadores de área, cujas práticas foram desenvolvidas em 19 (dezenove) escolas públicas. Em 2012, este quantitativo foi ampliado para 39 (trinta e nove) subprojetos, distribuídos em 18 (dezoito) campi.

Dois anos mais tarde, a UNEB participa da chamada pública - Edital $\mathrm{n}^{\circ}$ 001/2011/CAPES e aprova o Projeto Institucional, Ensino Superior e Educação Básica: articulando saberes, que teve como objetivo principal reconhecer o espaço da escola pública como um campo de experiência para a construção do conhecimento na formação de professores da educação básica, analisando a problemática educacional através do diálogo acadêmico entre a experiência universitária e de docentes em exercício. Este projeto contemplou 7 (sete) subprojetos em 5 (cinco) campi, 90 (noventa) bolsistas de iniciação, 12 (doze) bolsistas de supervisão e 11 (onze) unidades escolares.

participação em experiências metodológicas, tecnológicas e práticas docentes, de caráter inovador e interdisciplinar, que busquem a superação de problemas identificados no processo de ensinoaprendizagem; 5) incentivar escolas públicas de educação básica, mobilizando seus professores como coformadores dos futuros docentes e tornando-os protagonistas nos processos de formação inicial para o magistério; e 6) contribuir para a articulação entre a teoria e a prática necessárias à formação dos docentes, elevando a qualidade das ações acadêmicas nos cursos de licenciatura. Disponível em: <http://www.capes.gov.br/educacao-basica/capespibid/pibid>. Acesso em: 10 jun. 2016.

${ }^{4}$ A principal ação do projeto foi a inserção do licenciando no cotidiano das escolas para: 1) desenvolver atividades individuais e partilhadas com os professores da educação básica; 2) vivenciar práticas educativas formais em sala de aula; 3) participar de atividades escolares relacionadas à docência; 4) propor atividades inovadoras de ensino integradas ao cotidiano e às demandas da escola; 5) desenvolver projetos e questionamentos educacionais de forma articulada com a ação da escola; e 6) desenvolver habilidades e competências profissionais através de estudos, reflexão e convivência coletiva com os pares e professores da escola básica.

${ }^{5}$ Campus I (Salvador), Campus II (Alagoinhas), Campus IV (Jacobina), Campus X (Teixeira de Freitas), Campus XIII (Itaberaba), Campus XIV (Conceição do Coité), Campus XVI (Irecê), Campus XXI (Ipiaú) e Campus XXII (Euclides da Cunha).

${ }^{6}$ Campus I (Salvador), Campus IV (Jacobina), Campus VI (Caetité), Campus XI (Serrinha) e Campus X (Teixeira de Freitas). 
Foi a partir deste projeto institucional que o Campus XI da UNEB - Serrinha, ${ }^{7}$ através do subprojeto de Geografia: "O ensino de geografia e a formação dos professores: Diálogos e práticas entre estudantes da licenciatura em Geografia da UNEB, Campus XI e professores das escolas estaduais de ensino fundamental II e médio de Serrinha, Bahia", coordenado pela professora Marize Damiana, se inseriu no âmbito desta política pública de formação docente, contemplando 10 (dez) bolsistas de iniciação à docência, 2 (dois) bolsistas de supervisão e 2 (duas) escolas públicas.

Em 2013, com a aprovação do projeto institucional Da iniciação à docência: ressignificando a prática docente, o PIBID UNEB /CAPES passou a contemplar 49 (quarenta e nove) subprojetos, ${ }^{8}$ elaborados por professores de diversos cursos de licenciatura de 19 (dezenove) campi da Universidade do Estado da Bahia. Através do Edital CAPES 061/2013 aprovamos o subprojeto "Formação docente e Geografia escolar: das práticas e saberes espaciais à construção do conhecimento geográfico" (BATISTA; OLIVEIRA; PORTUGAL, 2013), cuja proposta de formação é objeto de discussão deste texto.

PIBID, formação de professores e Geografia Escolar: práticas, vivências e narrativas

Nossa intenção, ao escrever este texto, é apresentar as atividades propostas e experienciadas, no subprojeto "Formação docente e Geografia escolar: das práticas e saberes espaciais à construção do conhecimento geográfico", vinculado ao Programa Institucional de Bolsa de Iniciação à Docência (PIBID/CAPES), em desenvolvimento, na Universidade do Estado da Bahia - Campus XI, do Curso de Licenciatura em Geografia,

\footnotetext{
${ }^{7}$ Serrinha é um município do estado da Bahia, localizado na mesorregião do Nordeste baiano, à margem da BR 116 Norte e da BA 040, a 180 km (cento e oitenta quilômetros) de Salvador. Segundo dados do Censo Demográfico (IBGE, 2010) a população deste município é de 77.285 habitantes. Considerada a cidade polo do Território de Identidade do Sisal, Serrinha abriga importantes organismos da administração pública estadual e federal: Diretoria Regional de Educação - DIREC 12; Diretoria Regional de Saúde - $12^{\mathrm{a}}$ DIRES; Circunscrição Regional de Trânsito - 29 Ciretran; $16^{\circ}$ Batalhão da - JUCEB; Fundação Nacional de Saúde FUNASA; Instituto Brasileiro de Geografia e Estatística - IBGE; Receita Federal do Brasil; $5^{\mathrm{a}}$ Delegacia do Serviço Militar do Exército; Empresa Baiana de Desenvolvimento Agrícola - EBDA; Agência Estadual de Defesa Agropecuária da Bahia - ADAB; Companhia de Desenvolvimento e Ação Regional - CAR.

${ }^{8}$ Contemplando 1563 (mil quinhentos e sessenta e três) bolsistas de iniciação à docência, 234 (duzentos e trinta e quatro) bolsistas de supervisão, 108 (cento e oito) coordenadores de área, 100 (cem) escolas municipais e estaduais - e 4 (quatro) coordenadoras de gestão.
} 
desde março de 2014. Trata-se de uma proposta de formação que tem como principal objetivo articular a Universidade à escola básica, pelo desenvolvimento de ações situadas no campo de formação do professor de Geografia, e contempladas nas dimensões de ensino, pesquisa e extensão.

O objeto deste texto está ancorado nas experiências vivenciadas e narradas no devir da realização das ações didático-pedagógicas no PIBID de Geografia da UNEB/Campus XI, as quais comportam às dimensões - ética, epistemológica, conceitual, teórica, metodológica - necessárias à prática pedagógica do professor no âmbito da educação básica, no contexto da Geografia Escolar.

$\mathrm{Na}$ perspectiva de atender aos objetivos do PIBID, os quais incentivam a valorização do magistério e da escola pública, a formação inicial de professores para o exercício da docência na educação básica, bem como possibilitam a articulação e a aproximação entre a universidade (espaço de formação docente) e o sistema público de ensino (escola), locus da atuação profissional do professor, o referido subprojeto, cuja proposta está ancorada na potencialidade do uso didático-pedagógico das diversas linguagens, foi concebido a partir de cinco metas: 1) elevar a qualidade da formação inicial do professor de Geografia; 2) promover uma formação docente pautada no desenvolvimento de práticas de ensino de Geografia na escola básica que possam oportunizar o processo construtivo do ser professor, a partir do uso didático-pedagógico das diversas linguagens; 3) articular a universidade à escola básica, fomentando ações de ensino, pesquisa e extensão; 4) Promover a inserção dos licenciandos em Geografia no contexto das escolas da rede pública de Ensino (Fundamental II e Médio) dos municípios de Serrinha, Teofilândia e Conceição do Coité-BA; e 5) conhecer a escola, seus cotidianos e o universo da profissão docente, com a intenção de possibilitar aos licenciandos vivências formativas com vistas a garantir a aprendizagem da/na docência, ou seja, aprender a ser professor, o que, segundo Martins, constitui:

[...] um processo que vai muito além dos conhecimentos ditos técnicos e específicos com os quais entramos em contato na universidade, estando relacionado, também, com uma diversidade de outros conhecimentos 
que só se aprende quando há uma proximidade entre o universo acadêmico e o universo escolar. (2015, p. 41)

Assim, com o propósito de possibilitar outros modos de aprendizagem da docência, ancorados no método (auto)biográfico e nas estratégias metodológicas das diversas linguagens, as ações que envolvem o subprojeto "Formação docente e Geografia escolar: das práticas e saberes espaciais à construção do conhecimento geográfico" são: 1) Parcerias Universidade-Escola Básica; 2) Mapeamento da realidade escolar; 3) Espaços de Diálogos e Práticas; 4) Planejamento do trabalho pedagógico; 5) Ateliers Geográficos Temáticos; 6) Tateio experimental; 7) Pibid Itinerante; e 8) Atividades de campo, realizadas em 6 (seis) escolas - 3 (três) rurais e 3 (três) urbanas - de ensino fundamental e médio, de três municípios do Território de Identidade do Sisal: Conceição do Coité, Serrinha e Teofilândia, e envolvendo 57 (cinquenta e sete) bolsistas, subdivididos em três grupos, a saber: 45 (quarenta e cinco) bolsistas de iniciação à docência, 9 (nove) bolsistas de supervisão e 3 (três) bolsistas responsáveis pela coordenação.

A Parceria Universidade-Escola básica, que se caracterizou como a primeira ação do subprojeto, foi realizada no início de março de 2014, com os sujeitos envolvidos no programa e as escolas parceiras, tendo como objetivo formalizar a proposta, a partir da apresentação do calendário de atividades e do plano de ação a ser desenvolvido. A importância desta parceria escola-universidade, possibilitada pelo PIBID, é observada pela professora supervisora Adineide, que narra:

A participação no Programa Institucional de Bolsas de Iniciação à Docência - PIBID está proporcionando aos professores supervisores, pensar-refletir e inovar as práticas pedagógicas desenvolvidas no ensino da Geografia. Por se ter ciência da realidade do ensino público brasileiro e fragilidades nos cursos de formação de professores é que percebo o quanto a oportunidade em participar do Pibid me fez refletir sobre a importância que este programa representa para a minha trajetória formativa, pois se configura como um espaço de ressignificação de práticas e construção de novos saberes. (Adineide, Bolsista Supervisão, 2016) 
De fato, esta aproximação entre a escola e a universidade tem promovido ganhos significativos tanto para um como para o outro parceiro, pois a troca de saberes e de experiências tem possibilitado aos bolsistas de Iniciação à Docência (ID) aprender sobre a docência e, aos bolsistas de Supervisão, ressignificar práticas, a partir dessas vivências, entre o ir e vir à escola parceira e à universidade.

A segunda ação, denominada Mapeamento da realidade escolar, intencionou possibilitar aos bolsistas de ID diálogos com os sujeitos que compõem os espaços escolares parceiros. Esta atividade ocorreu no início da operacionalização do subprojeto, com o objetivo de inserir os bolsistas de ID nas escolas envolvidas no subprojeto, tendo em vista a realização de um mapeamento das mesmas, contemplando suas dimensões pedagógica, administrativa e de infraestrutura, de modo a caracterizar tais espaços de formação. Para tanto, foram realizadas observações do/no cotidiano escolar, além da aplicação de questionários e entrevistas junto a estudantes, professores e gestores das unidades escolares.

Ao narrar sobre os momentos vivenciados na ação do Mapeamento da realidade escolar, a bolsista de ID Manuela relatou que:

Quando as atividades do subprojeto foram iniciadas, a primeira delas consistia no mapeamento da escola para posterior caracterização. Mesmo tendo uma forte relação com o contexto de uma escola básica, nunca havia tido contato com a escola parceria e o lugar no qual eu estava naquele momento era de uma estudante pesquisadora, isto alterava a minha visão em relação à escola, que se tornara locus da pesquisa. A timidez e o medo eram grandes desafios a serem superados. Por muitas vezes me sentia em um beco sem saída, acompanhada da minha insegurança e muitas incertezas. Isso fez com que eu me acomodasse muitas vezes, pois enxergava as mudanças apenas pelo ponto de vista negativo. Mas com o tempo fui ganhando confiança, o contato com o contexto escolar através do PIBID me permitiu perceber que aquele é o ambiente no qual me sinto mais à vontade. Neste primeiro momento foi possível analisar a escola enquanto uma conjuntura de fatores que direcionam o fazer-pedagógico. A partir desta etapa inicial comecei a me relacionar com o ambiente escolar enquanto professora em formação. (Manuela, Bolsista ID, 2016) 
Neste excerto da narrativa escrita pela bolsista de ID Manuela, produzido na fase inicial de implantação do subprojeto na escola municipal Leandro Gonçalves da Silva, situada numa localidade rural do município de Conceição de Coité-BA, a professora em formação narra seus sentimentos - medo, insegurança, incertezas - que, comumente, emergem de uma situação nova e desconhecida. Entretanto, Manuela também destacou a necessidade de conhecer a escola e seu cotidiano e de planejar práticas para criar estratégias, tendo em vista garantir a apropriação do espaço escolar com vistas a melhor interagir e atuar nele.

Os Espaços de Diálogos e Práticas compreendem os momentos de formação realizados no âmbito da universidade, quando os bolsistas - de Supervisão, Iniciação à Docência e Coordenadores de área - planejavam, elaboravam, relatavam e avaliavam as práticas desenvolvidas no ensino de Geografia nas escolas parceiras, a partir da experimentação da docência na escola. Neste contexto, a universidade e a escola são concebidas como espaços-tempos de formação, em que são realizados estudos, planejamento e produção de materiais, tendo em vista o desenvolvimento de práticas de ensino ancoradas em diversas linguagens, concebidas enquanto dispositivos didáticopedagógicos e estratégias metodológicas de ensino dos conteúdos curriculares da Geografia nas escolas parceiras.

As práticas decorrentes das atividades desenvolvidas no âmbito dos Espaços de Diálogos e Práticas foram destacadas na narrativa do bolsista de ID Marcos, conforme fragmento a seguir:

Os Espaços de Diálogos e Práticas têm contribuído muito para o meu crescimento pessoal e profissional, visto que através do planejamento das atividades didáticas bem como a inserção das diversas linguagens no ensino de Geografia e de artefatos tecnológicos como instrumentos que potencializam o processo de ensino/aprendizagem vem construindo para o meu saber/fazer pedagógico. Diante disso, tenho notado o quão importante é o planejamento do professor antes da execução de suas atividades e o quanto que a troca de saberes e experiências contribuem para a construção de novas práticas. (Marcos, Bolsista ID, 2015) 
Ainda sobre a importância dos momentos de planejamento e avaliação do fazer pedagógico, realizados no âmbito dos Espaços de Diálogos e Práticas, enfatizada na narrativa do bolsista de ID Marcos, Madalena, professora bolsista de Supervisão, narrou que os mesmos têm possibilitado uma formação continuada, necessária ao exercício da profissão, conforme segue:

\begin{abstract}
Diante das contribuições advindas das vivências formativas do Pibid, destaco os momentos denominados de Espaços de Diálogos e Práticas, nos quais são discutidos textos que tratam de temas ligados às diversas linguagens no ensino de Geografia. As referidas sessões de estudos possibilitam aos professores supervisores a retomada de leitura e reflexões que já foram feitas em momentos da formação inicial, mas, nesse momento, apontam um novo olhar para compreender e relacionar a teoria à prática diante das experiências dos professores. Percebo ainda as potencialidades desses momentos que são diversas, pois além de oportunizar e fortalecer teoricamente os conhecimentos dos professores em formação inicial e continuada - bolsistas ID e de Supervisão promovem a retomada dos estudos acadêmicos e incentivo à busca de novos projetos de formação para vida profissional. São importantes esses estudos, pois representam a retomada ainda de participação em eventos e produções acadêmicas. (Madalena, Bolsista Supervisão, 2016)
\end{abstract}

As reflexões tecidas pelos bolsistas Marcos e Madalena evidenciam a relevância e as contribuições dos Espaços de Diálogo e Práticas, que se constituem em momentos de formação inicial e continuada para os professores envolvidos no programa. Segundo a professora Madalena, o regresso à instituição onde vivenciou a formação inicial para a docência, agora na condição de formadora, reacendeu seu desejo de continuar os estudos e de colocar em prática projetos de formação profissional.

O Planejamento do Trabalho Pedagógico configurou-se em momentos de (re)orientação do trabalho, à luz de discussões realizadas nos encontros formativos, no sentido de melhorar as práticas desenvolvidas nas escolas parceiras e contribuir com a formação inicial dos bolsistas de ID. Esta ação está diretamente articulada às ações Espaços de Diálogos e Práticas e Atelier Geográfico Temático, conforme destaca a professora Adineide dos Anjos, bolsista de Supervisão que atua na Escola Ana Oliveira, no município de Teofilândia. 
Ter planejado e realizado as Oficinas de Alfabetização Cartográfica com os bolsistas ID do Pibid que me acompanham na Escola Ana Oliveira, foi de grande satisfação, pois os alunos ficaram encantados com a nossa proposta, a qual contemplou atividades lúdicas, jogos, brincadeiras envolvendo elementos da Cartografia, estimulando a participação e envolvimento de alunos desmotivados, desinteressados e com histórico de rebeldia. As nossas oficinas de cartografia só foram possíveis por conta das situações vividas nos Espaços de Diálogos e Práticas, no momento do Planejamento do trabalho pedagógico. Assim, ficamos muito satisfeitos com os resultados do nosso projeto decorrente do II Atelier Geográfico Temático, que teve como linguagem norteadora, a Cartografia. Enfim, conseguimos atingir nossos objetivos ao destacar a importância da Cartografia na aprendizagem da Geografia e, também, despertar o interesse dos alunos. (Adineide, Bolsista Supervisão, 2016)

Na ação intitulada Tateio experimental, são oportunizados momentos em que os professores de Geografia, em formação inicial e continuada, apoiados em procedimentos metodológicos e instrumentos pedagógicos, como a "hora da conversa", os "círculos de leitura" e os "relatos de experiências" para superar dicotomias, fazem aflorar problematizações, reflexões e indagações sobre os conhecimentos adquiridos entre os espaços da universidade e das escolas parceiras, principalmente articulando, a partir das ações do subprojeto, os saberes específicos da ciência geográfica e os saberes pedagógicos aprendidos na universidade ao saber-fazer na escola. Sobre essas experiências e práticas, as bolsistas Manuela (Iniciação à Docência) e Maristela (Supervisão), narraram:

Através desse projeto desvinculo-me de um discurso pessimista da escola, para me apropriar de um contexto de transformação, que me condiciona uma formação diferenciada do que a licenciatura pode proporcionar. Isto não significa que irei me acomodar, mas que constantemente sou instigada a fortalecer as raízes do conhecimento não somente através de base teórica, mas do planejamento de práticas que fortalecem e estreitam minha relação com o contexto da escola básica. (Manuela, Bolsista ID, 2016)

É visível o quanto o meu ingresso no PIBID como professora supervisora tem contribuindo com a minha formação profissional, para a formação 
de meus alunos que adoram participar das atividades e estão sempre dispostos a colaborarem e para a visibilidade da escola e da educação rural enquanto espaço de construção de conhecimentos relacionados também às vivências dos alunos e de identidades de sujeitos rurais. (Maristela, Bolsista Supervisão, 2016)

Os excertos narrativos das professoras Manuela e Maristela a respeito das situações experienciadas nos momentos do Tateio experimental sinalizam que as ações do subprojeto têm possibilitado uma reflexão sobre a formação e a atuação docentes, bem como sobre as práticas pedagógicas, na área de Geografia, a partir do cotidiano.

O Atelier Geográfico Temático caracteriza-se como um espaço que permite aos bolsistas de ID e de Supervisão, bem como aos professores de Geografia das escolas parceiras, a reflexão sobre o ensino de conceitos, temas, fenômenos e processos geográficos, no âmbito da Geografia Escolar. Esta ação também contempla o planejamento de sequências didáticas, tendo em vista a realização de práticas de ensino atreladas às diversas linguagens - música, literatura, charge, desenho, cartografia, gráficos, cinema, histórias em quadrinhos, tiras, pintura, escultura, dentre outras - como estratégias metodológicas e artefatos didáticos de abordagem dos conteúdos do currículo escolar, numa dimensão de problematização, de interdisciplinaridade, de transdisciplinaridade e de contextualização, favorecendo a formação e a atuação do professor de Geografia.

Sobre as experiências vivenciadas no devir das práticas do I Atelier Geográfico Temático $^{9}$ - A linguagem cinematográfica na sala de aula: dispositivo didático-pedagógico para ensinar e aprender conceitos e temas da Geografia Escolar, os bolsistas Marcos e Manuela relataram:

\footnotetext{
9 No âmbito do I Atelier Geográfico Temático, algumas propostas de sequências didáticas foram desenvolvidas, a partir da exibição das seguintes películas fílmicas: “Morte e Vida Severina” (MELO NETO, 2012), "Cotidiano-indústria da seca" (MAURíCIO RICARDO, 2014), "Calango Lengo - morte e vida sem ver água” (MILLER, 2008); "Vida Maria” (RAMOS, 2006); “Era uma vez...” (SILVEIRA, 2008); "O Núcleo" (AMIEL, 2003); "O Caminho das Nuvens" (AMORIM, 2003); e "Tainá: uma aventura na Amazônia" (LAMARCA; BLOCH, 2001).
} 
[...] essa atividade me permitiu um novo olhar sobre a utilização de películas fílmicas em sala de aula, talvez porque no meu processo de escolarização essa não tenha sido uma prática tão comum e quando utilizada era de forma errônea, visto que era algo dissociado dos conteúdos de Geografia. A busca por películas fílmicas que contemplassem os conteúdos trabalhados pela professora supervisora me fez perceber o quanto o cinema, inclusive o nacional, pode abarcar conteúdos da Geografia na escola. (Marcos, Bolsista ID, 2016)

Através da proposta do I Atelier Geográfico Temático, a qual teve por objetivo instigar a apreensão dos conceitos e temas da Geografia através da linguagem cinematográfica e, apesar da minha imaturidade, pude adentrar e me apropriar do contexto da sala de aula, pensar e planejar sequências didáticas em conjunto com outras bolsistas de ID e supervisão; constituindo assim minha identidade enquanto docente. Este Atelier propiciou pensar o ensino de Geografia à luz das diversas linguagens e, neste caso, a linguagem cinematográfica, o que me possibilitou refletir acerca da escolha de um artefato didáticopedagógico de acordo com a idade-etapa-ano de escolarização dos alunos e os seus lugares de vivência, para que a atividade proposta não fosse entendida, pelos estudantes como um mero passatempo, mas que proporcionasse a construção de um conhecimento de modo lúdico, consolidado e contextualizado. (Manuela, Bolsista ID, 2016)

Na experiência formativa no âmbito do I Atelier Geográfico Temático, que contemplou a linguagem cinematográfica como artefato didático-pedagógico para abordar os conteúdos da Geografia contemplados nos currículos das escolas, os bolsistas de ID Marcos e Manuela destacaram a potencialidade desta linguagem como estratégia didática do ensino de Geografia e a necessidade de considerar, no momento do planejamento, a escolha do filme, os conteúdos e a idade-etapa-ano de escolarização dos alunos, para que esta prática não seja compreendida "como um mero passatempo", pois o cinema em sala de aula se configura como uma linguagem lúdica que possibilita desenvolver práticas interdisciplinares, ao fazer uso de códigos, convenções e ideologias da cultura de quem o produz, permitindo o tratamento de mais de uma temática em uma única película fílmica.

No Il Atelier Geográfico Temático - A linguagem cartográfica na Geografia Escolar: saberes, conceitos e temas, foram planejadas e realizadas intervenções com a linguagem cartográfica, considerada importante na Geografia escolar, uma vez que, por meio dela, 
muitos conceitos, temáticas e temas da geografia podem ser discutidos e representados em mapas, gráficos, quadros, tabelas, infográficos e croquis, dentre outros.

Sobre a experiência com esta linguagem, Manuela relatou:

O segundo Atelier abordou a Cartografia enquanto ciência e linguagem. Esta foi uma temática sabiamente escolhida e fundamental na minha formação, tendo em vista a importância desta ciência/linguagem no ensino de Geografia. O contato com um vasto arcabouço teórico disponibilizado me possibilitou aprender Cartografia a partir de uma alfabetização cartográfica ancorada nas noções de lateralidade, espacialidade, orientação, escala. As atividades pensadas e planejadas para socialização com os docentes da escola durante as oficinas (geo)cartográficas me instigaram a buscar maior conhecimento cartográfico, o qual possuía muitas lacunas, mas no desenvolvimento dessas atividades tive a oportunidade de consolidar este conhecimento a partir da percepção de minhas dificuldades, repensando minha formação, a partir do ideário de que só se ensina aquilo que se sabe. (Manuela, Bolsista ID, 2016)

E a também bolsista de ID, Alana Barros, assim complementou:

O planejamento das atividades inseridas na proposta do II Atelier Geográfico Temático foi um momento oportuno para explorar possibilidades e estratégias de ensino ancoradas no uso didático da Cartografia, a partir de diversas práticas e atividades que envolviam diversos conceitos/noções: lateralidade, orientação, direção, escalas, legenda, coordenadas geográficas, entre outros elementos necessários à alfabetização cartográfica, tendo em vista a aprendizagem da leitura, interpretação e compreensão de mapas. Eu gostei muito da segunda atividade que correspondeu à realização de oficinas didático-pedagógicas na escola parceira, nas quais foram realizadas práticas com o uso dos recursos cartográficos, cujo principal objetivo foi enfatizar a importância dos saberes cartográficos, como tema que transversaliza os componentes que compõem o currículo escolar. Desse modo, intencionamos desconstruir a ideia de que mapas, maquetes, cartas, croquis, globo terrestre, gráficos/tabelas e quadros são recursos de uso específico da Geografia. (Alana Barros, Bolsista ID, 2015)

Os excertos da narrativa de Manuela e Alana sinalizam a importância do processo de alfabetização cartográfica, na formação docente e na escola, pois, segundo Almeida e 
Passini: “[...] preparar o aluno para essa leitura deve passar por preocupações metodológicas tão sérias quanto à de se ensinar a ler e escrever, contar e fazer cálculos matemáticos" (ALMEIDA; PASSINI, 1994, p. 15).

Já no III Atelier Geográfico Temático - Geografia em imagens: abordagem de fatos, fenômenos e processos geográficos, pautamos nosso planejamento em uma sequência de atividades utilizando os recursos das linguagens imagéticas - charges, tiras, cartuns, desenhos, histórias em quadrinhos, fotografias, infográficos e gráficos - como dispositivos didático-pedagógicos relevantes em sala de aula para ensinar e aprender os conceitos geográficos de lugar, paisagem, região, território e espaço.

Sobre esta experiência, a bolsista de ID Mikaelly narrou:

[...] A partir das discussões e planejamentos sobre o uso didáticopedagógico das linguagens imagéticas - charge, cartum, histórias em quadrinhos (HQs), desenho e infográficos - elaboramos uma proposta pedagógica no formato de oficinas para ser desenvolvida na Escola Ana Oliveira, denominada "Geografia e gêneros textuais - charges, cartuns, HQs, tiras, infográficos e fotografias: a aprendizagem diante dos olhos" que teve como objetivos compreender a importância dos gêneros textuais como uma forma de linguagem usada para entender as diferentes situações vividas pela população em representações locais e globais do espaço geográfico; ensinar Geografia por meio destas linguagens visando ampliar os horizontes da aprendizagem; distinguir as características, as desigualdades e as semelhanças socioeconômicas e culturais dos diferentes espaços geográficos. Os conteúdos trabalhados foram: continente europeu, globalização e atualidade. [...] Foi, sem dúvida, uma experiência com resultados bastante significativos. [...] A partir do uso dos gêneros textuais na sala de aula de Geografia, podemos afirmar que os alunos foram bem participativos e criativos, todos se empenharam, leram e escreveram até mesmo, os tímidos se envolveram e fizeram parte desse processo. Nota-se que o uso desses artefatos didático-pedagógicos tem uma grande potencialidade na sala de aula porque instigam o aluno a pensar e refletir sobre questões da sociedade, além de fazê-lo perceber a Geografia presente no seu cotidiano. (Mikaelly, Bolsista ID, 2016)

A leitura e a interpretação do excerto da narrativa da bolsista de ID Mikaelly sinaliza a importância de estratégias metodológicas e das atividades de ensino ancoradas em textos imagéticos para ensinar e aprender Geografia na sala de aula da escola básica, 
pois os alunos ficam motivados a aprender, mediados pela curiosidade e seduzidos pela riqueza de elementos gráficos: cores, traços, linhas, variedades de temas e fontes, disponíveis nas imagens, o que aguça a sua imaginação e possibilita múltiplas aprendizagens.

O Pibid Itinerante, concebido como uma atividade de caráter formativo-criativo, caracteriza-se como um momento de troca de experiências, através do fomento de atividades que são desenvolvidas em conjunto com os alunos e professores das escolas parceiras, mediante visitas dos grupos de bolsistas. Nessa ação itinerante, os bolsistas vivenciam momentos de aprendizagens diversas decorrentes das visitas nas escolas parceiras, pela realização e a participação em atividades formativas, como seminários e palestras ministradas e desenvolvidas, tanto nas escolas parceiras, quanto em outros espaços adjacentes às escolas vinculadas ao subprojeto. Sobre a experiência vivenciada nesta ação, a professora supervisora Adineide narra que os bolsistas foram:

[...] convidados para realizar oficinas de formação para professores de Geografia nos Municípios de Barrocas e Teofilândia no estado da Bahia, tudo fruto de um programa [PIBID/Geografia] que veio para fazer acontecer. [...] É uma realização pessoal, profissional se tornando realidade e impossível de ser transcrita nessas linhas porque a satisfação é infinita. (Adineide, Bolsista Supervisão, 2016)

Segundo a professora Adineide, no excerto da sua narrativa, as ações do Pibid Itinerante, realizadas no começo do ano letivo de 2016, possibilitaram aos bolsistas de ID a ampliação de seus espaços de formação e de atuação (universidade/escola parceira do PIBID), uma vez que muitos deles foram convidados a realizar seminários e oficinas em outras escolas dos municípios da região do Território do Sisal, que não são parceiras diretas do nosso subprojeto.

A Atividade de campo é compreendida, no âmbito do referido subprojeto, como uma estratégia metodológica necessária ao processo de ensino-aprendizagem da Geografia, pois favorece a abordagem de conceitos e temas da Geografia para além da sala de aula. Esta ação foi proposta visando aproximar teoria e prática, através do 
desenvolvimento do olhar crítico-problematizador, sobretudo no que concerne à abordagem de questões vinculadas aos espaços de vivência do aluno, a partir dos lugares da escola e do seu entorno até os lugares e cotidianos da cidade sede do município.

A proposta de realização de trabalhos de campo, no âmbito do subprojeto, intenciona, desse modo, promover a aproximação do conhecimento geográfico do cotidiano do aluno, a partir da prática de observação, descrição, análise e crítica da paisagem e de outras questões, conceitos e temas da Geografia Escolar.

Sobre a potencialidade do trabalho de campo, enquanto técnica/estratégia metodológica que possibilita o acesso dos estudantes à realidade do contexto em estudo, Portugal e Souza (2013) ressaltam que:

O principal objetivo do trabalho de campo, no âmbito da prática pedagógica no ensino da Geografia na Educação Básica, é oportunizar aos alunos apreender conceitos e temas da Ciência Geográfica, estabelecendo relação entre as situações experienciadas na sala de aula e as aprendizagens em campo, tendo em vista maior apreensão do conteúdo abordado. (PORTUGAL; SOUZA, 2013, p. 126)

Trata-se, portanto, de uma metodologia imprescindível à educação geográfica, pois, além de favorecer o ensino interdisciplinar de conteúdos e temas, possibilita, também, o desenvolvimento de habilidades e competências, aprofunda os conteúdos/saberes desenvolvidos em sala de aula e aproxima os conhecimentos geográficos da realidade do estudante, como destacado na narrativa da bolsista de ID Mikaelly:

O trabalho de campo é uma importante prática para a contextualização dos conceitos e temas da Geografia, acreditamos que essa metodologia pode contribuir de forma significativa no processo de ensino aprendizagem, instigando o aluno a observar de maneira mais crítica a realidade que o cerca, de forma que ele possa compreender que a paisagem visualizada é resultado das relações sociais, políticas e econômicas, a qual não se manifesta de forma concreta. [...] Diante disto, é perceptível que o trabalho de campo é um instrumento que possibilita o educando fazer observações e atrelar o que foi visto na sala de aula e a 
prática in loco. Sendo assim, o trabalho de campo tem suas potencialidades e desafios e o professor, enquanto mediador do conhecimento, tem que estar disposto a pensar e propor novas práticas e metodologias no Ensino de Geografia, e com certeza o trabalho de campo é uma ótima escolha metodológica. Isso eu tenho aprendido com as experiências no PIBID. (Mikaelly, Bolsista ID, 2016)

No âmbito do subprojeto "Formação docente e Geografia escolar: das práticas e saberes espaciais à construção do conhecimento geográfico", as Atividades de Campo configuraram-se, portanto, como importantes ações que visam o ensino e a aprendizagem de conceitos da Geografia, que promovem a apreensão de novos saberes e aproximam os conteúdos curriculares da Geografia do cotidiano dos alunos, favorecendo uma aprendizagem mais significativa, uma vez que o trabalho de campo favorece a conexão entre a teoria na sala de aula e a realidade vivenciada no campo, in loco, reforçando, desse modo, a potencialidade e a pertinência do trabalho de campo no processo de educação geográfica, como procedimento metodológico de percepção e compreensão dos conteúdos discutidos em sala de aula, de modo interdisciplinar.

Assim sendo, a interdisciplinaridade, a contextualização e a transdisciplinaridade estão presentes nas ações do referido subprojeto, quando são possibilitadas as discussões de temas e conceitos da Geografia Escolar, o planejamento e a realização de práticas de ensino a partir das diversas linguagens, potencializando, desse modo, distintos conteúdos que, em interação, produzem outros conhecimentos, integrando os sujeitos que aprendem, difundindo e transformando esses conhecimentos, articulando o vivido e o investigado, refletindo, narrando e escrevendo, pois:

O Programa Institucional de Bolsas de Iniciação à Docência PIBID/UNEB/CAMPUS $\mathrm{XI}$ tem propiciado grandes aprendizagens geográficas, dando a oportunidade de estarmos atuando em sala de aula mesmo antes da conclusão do Ensino Superior, o que tem uma relevância para a nossa formação acadêmica. Dentro do projeto desenvolvemos várias práticas que tem contribuído para a melhoria do Ensino de Geografia, e, é nessa perspectiva que seguimos em frente. Essas práticas com certeza irão refletir na nossa carreira profissional, enquanto mediador do conhecimento. (Mikaelly, Bolsista ID, 2016) 
Assim, a interdisciplinaridade contribui com a prática docente, pois, tendo como princípio do trabalho integrador o esforço teórico-prático de compreender a realidade, propõe alternativas para o ensino de conceitos, conteúdos e temas da Geografia, como nos asseguram Fazenda (2003), Pontuschka, Paganelli e Cacete (2007), articulado às diversas linguagens, como afirmam Portugal e Oliveira (2009).

Neste contexto, as diversas linguagens podem ser vistas como artefatos/dispositivos/recursos e objetos de conhecimento, meios de comunicação, de expressão de sentimentos e de pensamentos, porque aguçam reflexões, sobretudo no que concerne à ciência geográfica, quando as diversas linguagens, como a música, a literatura, a charge, o desenho, a cartografia, os gráficos, o cinema, as histórias em quadrinhos, as tiras, a pintura, a escultura, dentre outras, podem ser utilizadas como estratégias metodológicas para ensinar e aprender conceitos e temas da Geografia na escola.

\section{Ações e desdobramentos do PIBID de Geografia no Sertão do Sisal: considerações finais}

A partir das ações do subprojeto "Formação Docente e Geografia Escolar: das Práticas e Saberes Espaciais à Construção do Conhecimento Geográfico" (PIBID/CAPES), do curso de Licenciatura em Geografia da UNEB, Campus XI, Serrinha-BA, retratadas através das narrativas dos bolsistas sobre as atividades realizadas no devir da sua proposta, podemos afirmar que o PIBID tem se configurado como um importante programa do conjunto de políticas públicas de formação docente, ao valorizar a docência e a profissão do magistério, por possibilitar a articulação de saberes entre o espaço de formação inicial docente e o espaço de atuação profissional do professor, propondo práticas inovadoras para a inserção dos professores em formação na realidade cotidiana do trabalho docente.

As escolas parceiras dos municípios atendidos pelo subprojeto do PIBID têm percebido a necessidade e a importância de metodologias inovadoras no ensino, o que tem proporcionado aos estudantes da educação básica uma nova forma de aprender Geografia. Para os bolsistas de Iniciação à Docência, o subprojeto tem contribuído com a 
valorização do magistério e possibilitado uma formação docente mais articulada à realidade do espaço escolar porque as ações têm permitido aos bolsistas de ID mais tempo de permanência nas escolas e um aprendizado mais abrangente da profissão. Além disso, o PIBID de Geografia do Campus XI/UNEB tem contribuído para a reafirmação dos graduandos e dos professores supervisores pela opção da licenciatura em Geografia, como enfatiza a professora Supervisora Maristela, que atua numa das escolas parceiras localizadas em espaços rurais, ao dizer que:

Fazer parte da família PIBID é uma grande satisfação. Quando fui informada/convidada a concorrer o edital da Capes objetivando me tornar professora supervisora do PIBID foi algo que de início me deixou apreensiva e reflexiva, pois eu estava retornando de uma licença maternidade e seria mais um 'trabalho' para uma recém-mãe. Mas, eu tinha a consciência que o PIBID seria algo muito bom para minha formação pessoal e profissional, seria a oportunidade que eu tinha para dar continuidade a minha formação enquanto educadora que leciona em escolas rurais. Era a oportunidade que eu estava tendo de contribuir para dar visibilidade à educação rural, a uma escola da roça. Sabia que seria um grande desafio, mas eu não poderia deixar passar esta oportunidade. [...] Hoje, tenho o prazer de dizer que o PIBID, além de contribuir com a minha prática pedagógica, também tem contribuído com a minha formação continuada, me ajudou a ingressar no curso stricto sensu no Programa de Pós-graduação em Educação e Contemporaneidade da Universidade do Estado da Bahia, Campus I, Salvador e a oportunidade de pesquisar e contribuir com os estudos no âmbito da educação geográfica, privilegiando os saberes cotidianos dos alunos da escola rural. (Maristela, Bolsista Supervisão, 2016)

Além de reafirmar que o PIBID tem possibilitado a formação continuada para o exercício docente, a professora Maristela sinaliza a importância de sua escola fazer parte deste programa, que privilegia a iniciação à docência, principalmente porque deu visibilidade às atividades didático-pedagógicas desenvolvidas nas escolas localizadas em territórios rurais.

Como o nosso subprojeto do PIBID sugere, o conhecimento geográfico também ocorre em práticas e saberes espaciais, ancorados nas diversas linguagens e na reflexão sobre o ser e o fazer docente, pois todas as atividades desenvolvidas no âmbito do 
subprojeto promovem o contato do licenciando com a sala de aula, bem como da universidade com a escola básica, aproximando esses espaços, cujo intuito é garantir aos graduandos em Geografia saberes - específicos da ciência geográfica e pedagógicos necessários ao exercício da docência, além de possibilitar aos professores supervisores:

[...] ressignificar suas identidades profissionais, pois estas [...] não são algo acabado: estão em constante construção, a partir das novas demandas que a sociedade coloca para a escola e a ação docente. Formadores e formandos encontram-se constantemente construindo suas identidades individuais e coletivas. (PIMENTA; LIMA, 2004, p. 127)

No PIBID, os professores coordenadores, os professores em formação inicial e os professores-supervisores são convocados a refletir sobre a atuação profissional docente e, sobretudo, problematizar o cotidiano escolar, a didática geográfica à luz de teorias específicas, o que pode oportunizar outras formas de ver, agir e ser, enquanto profissionais da área da educação em geografia. Nesse sentido, são autores, coautores e sujeitos de sua própria formação.

A partir da análise e da interpretação das narrativas dos bolsistas sobre as atividades realizadas no devir da proposta de investigação-formação do subprojeto Formação Docente e Geografia Escolar: das Práticas e Saberes Espaciais à Construção do Conhecimento Geográfico (PIBID/CAPES), do curso de Licenciatura em Geografia da UNEB, Campus XI, Serrinha-BA, é possível afirmar que as ações potencializaram diferentes modos de pensar, propor e fazer a docência em Geografia na Educação Básica, a partir dos princípios da dimensão da problematização, da interdisciplinaridade, da transdisciplinaridade e da contextualização, como propostas que favorecem a formação e a atuação do professor de Geografia, mediadas por diversas linguagens.

Este programa, que faz parte de uma política pública de formação docente, tem possibilitado potencializar a formação inicial do professor de Geografia para o exercício da docência na educação básica, a partir de práticas diversas e inovadoras, ancoradas nas diversas linguagens como artefatos didático-pedagógicos e estratégias de ensino. 
No contexto da proposta do referido subprojeto, as narrativas de formação evidenciam a importância do programa, no âmbito de uma política pública, que favorece a inserção dos professores em formação inicial em seu futuro espaço de atuação profissional, possibilitando-lhes conhecer o cotidiano da escola e do trabalho docente, bem como propiciando a valorização do magistério e o alcance, pelos professores e bolsistas de Supervisão, de uma formação continuada na escola básica.

As oito ações do subprojeto - Parceria Universidade-Escola Básica; Mapeamento da realidade escolar; Espaços de Diálogos e Práticas; Planejamento do trabalho pedagógico; Tateio experimental; Atelier Geográfico Temático; Pibid itinerante e Atividades de campo, desenvolvidas durante o biênio 2014-2016 nas seis escolas parceiras, localizadas tanto em espaços rurais como urbanos, nos três municípios - Conceição do Coité, Serrinha e Teofilândia -, proporcionaram momentos formativos significativos, pela aproximação da universidade e escola básica e envolveram os cinquenta e sete bolsistas - quarenta e cinco de Iniciação à Docência, nove bolsistas de Supervisão e três bolsistas responsáveis pela Coordenação - em ações de ensino, pesquisa e extensão, contribuindo, especialmente, para a ressignificação de suas identidades profissionais.

Enfim, as narrativas produzidas pelos bolsistas de Iniciação à Docência e de Supervisão, vinculados ao subprojeto Formação Docente e Geografia Escolar: das Práticas e Saberes Espaciais à Construção do Conhecimento Geográfico, sobre as experiências formadoras rememoradas versam sobre as práticas desenvolvidas, as vivências formativas, os saberes adquiridos e ressignificados no exercício da docência, a partir das contribuições das ações do PIBID, ancoradas nas diversas linguagens, que garantiram uma abordagem centrada na problematização, tendo em vista a construção de conceitos e temas da Geografia Escolar e a análise de fenômenos, fatos e processos geográficos, de maneira lúdica e significativa para os alunos da Educação Básica.

\section{Referências}

ALMEIDA, Rosangela Doin de. PASSINI, Elza Yasuko. O espaço geográfico: ensino e representação. 5. ed. São Paulo: Contexto, 1994. 
AMIEL, Joh. O Núcleo [filme-vídeo]. Roteiro de John Rogers . Estados Unidos: Paramount Pictures, 2003. 1 DVD, 135 min.

AMORIM, Vicente. O caminho das nuvens. [filme-vídeo]. Roteiro de David França Mendes. Produzido por Bruno Barreto e Ângelo Gastal. Trilha sonora de André Abujamra. Distribuição de Disney / Buena Vista, 2003. 1 DVD . 86 min.

BATISTA, Marize Damiana Moura Batista; OLIVEIRA, Simone Santos de; PORTUGAL, Jussara Fraga. Formação docente e Geografia escolar: das práticas e saberes espaciais à construção do conhecimento geográfico. Serrinha-BA, 2013. Programa Institucional de Bolsas de Iniciação à Docência. Edital CAPES 061/2013. Departamento de Educação da Universidade do Estado da Bahia - UNEB, Campus XI, Serrinha-BA, 2013, 23 p. (Digitalizado).

FAZENDA, Ivani Catarina. A interdisciplinaridade: qual o sentido? São Paulo: Paulus, 2003.

INSTITUTO BRASILEIRO DE GEOGRAFIA E ESTATÍSTICA (IBGE) - Censo Demográfico, 2010. Rio de Janeiro: IBGE, 2011. Disponível em: < http://www.ibge.gov.br/censo2010/. Acesso em: 21 abr. de 2011.

LAMARCA, Tânia; BLOCH, Sérgio. Tainá - uma aventura na Amazônia. [filme-vídeo]. Roteiro de Cláudia Levay e Reinaldo Moraes. Brasil: Art Films MAM, 2001. 1 DVD, 90 min.

MARTINS, Rosa Elisabete M. W. Pibid de Geografia da FAED/UDESC: experimentações na iniciação à docência. In: MARTINS, Rosa Elisabete M. W.; ROSSATO, Luciana. (Orgs.). Reflexões sobre as experiências do PIBID na UDESC. Santa Cruz do Sul, SC: EDUNISC, 2015. p. 41-56.

MAURÍCIO RICARDO. Cotidiano-indústria da seca. [Charge animação-vídeo]. Disponível em: <www.youtube.com/watch?v=v-goUHUW6gY. 1 min>. Acesso em: 09 out. 2014.

MELO NETO, João Cabral de. Morte e Vida Severina. [filme animação 3D-vídeo]. Adaptação do cartunista Miguel Falcão. Direção de Afonso Serpa. Produção de Roger Burdino. Trilha sonora de Lucas Santana. São Paulo: Fundação Joaquim Nabuco, 2012. 1 DVD. Som, 56 min.

MILLER, Fernando. Calango Lengo - morte e vida sem ver água. [filme animação-vídeo]. MR Produções Artísticas. Estúdios Álamo. Campo 4 Desenhos Animados. Ministério da Cultura: Brasil, 2008, Sony Pictures, 2008, 1 DVD, 10 min. 
PIMENTA, Selma G.; LIMA, Maria. S. Lucena. (Orgs.). Estágio e docência. São Paulo: Cortez, 2004.

PONTUSCHKA, Nídia Nacib; PAGANELLI, Tomoko Lida; CACETE, Núria Hanglei. Para ensinar e aprender Geografia. São Paulo: Cortez, 2007.

PORTUGAL, Jussara Fraga; SOUZA, Elizeu Clementino de. Ensino de Geografia e o mundo rural: diversas linguagens e proposições metodológicas. In: CAVALCANTI, Lana de Souza (Org.). Temas da Geografia na escola básica. Campinas, SP: Papirus, 2013. p. 95-134.

PORTUGAL, Jussara Fraga; OLIVEIRA, Simone Santos de. Dialog - diversas linguagens, formação docente e ensino de Geografia. Serrinha: UNEB, 2009. (versão digitalizada)

PROGRAMA de Bolsas de Iniciação à Docência (PIBID). Brasília: CAPES, 2016. Disponível em: <http://www.capes.gov.br. Acesso em: 10 jun. 2016.

RAMOS, Márcio. Vida Maria. [filme animação-vídeo]. VIACG Produção Digital e TRIO Filmes. Fortaleza, Ceará: 2006, Sony Pictures, 1 DVD, 9 min.

SILVEIRA, Bueno. Era uma vez... [filme-vídeo]. Produção de Conspiração Filmes. Roteiro de Patrícia Andrade e Domingo Oliveira. Brasil, Sony Pictures, 2008, 1 DVD, 117 min.

TERRITÓRIOS DE IDENTIDADE. Salvador: SEPLAN, 2013. Disponível em: <http://www.seplan.ba.gov.br/modules/conteudo/conteudo.php?conteudoz. Acesso em: og out. 2013. 